\title{
Impurity Electron Core Effect in ORMAK
}

\author{
D. L. Shaeffer
}




\section{DISCLAIMER}

This report was prepared as an account of work sponsored by an agency of the United States Government. Neither the United States Government nor any agency Thereof, nor any of their employees, makes any warranty, express or implied, or assumes any legal liability or responsibility for the accuracy, completeness, or usefulness of any information, apparatus, product, or process disclosed, or represents that its use would not infringe privately owned rights. Reference herein to any specific commercial product, process, or service by trade name, trademark, manufacturer, or otherwise does not necessarily constitute or imply its endorsement, recommendation, or favoring by the United States Government or any agency thereof. The views and opinions of authors expressed herein do not necessarily state or reflect those of the United States Government or any agency thereof. 


\section{DISCLAIMER}

Portions of this document may be illegible in electronic image products. Images are produced from the best available original document. 
Printed in the United States of America. Available from National Technical Information Service

U.S. Department of Commerce

5285 Port Royal Road, Springfield, Virginia 22161

Price: Printed Copy $\$ 3.50$, Micruliche $\$ 3.00$

This report was prepared as an account of work sponsored by the United States Government. Neither the United States nor the Energy Research and Development Administration/United States Nuclear Regulatory Commission, nor any of their employees, nor any of their contractors, subcontractors, or their employees, makes any warranty, express or implied, or assumes any legal liability or responsibility for the accuracy, completeness or usefulness of any information, apparatus, product or process disclosed, or represents that its use would not infringe privately owned rights. 
Contract No. W-7405-eng-26

FUSION ENERGY DIVISION

IMPURITY ELECTRON CORE EFFECT IN ORMAK

D. L. Shaeffer

Date Published - March 1977

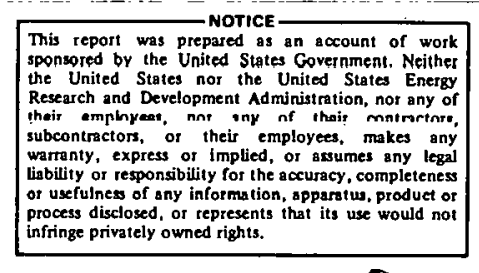

Prepared by the

OAK RIDGE NATIONAL LABORATORY

Oak R1dge, Tennessee 37830

operated by

UNION CARBIDE CORPORATION

for the

ENERGY RESEARCH AND DEVELOPMENT ADMINISTRATION 
THIS PAGE

\section{WAS INTENTIONALLY \\ LEFT BLANK}


TABLE OF CONTENTS

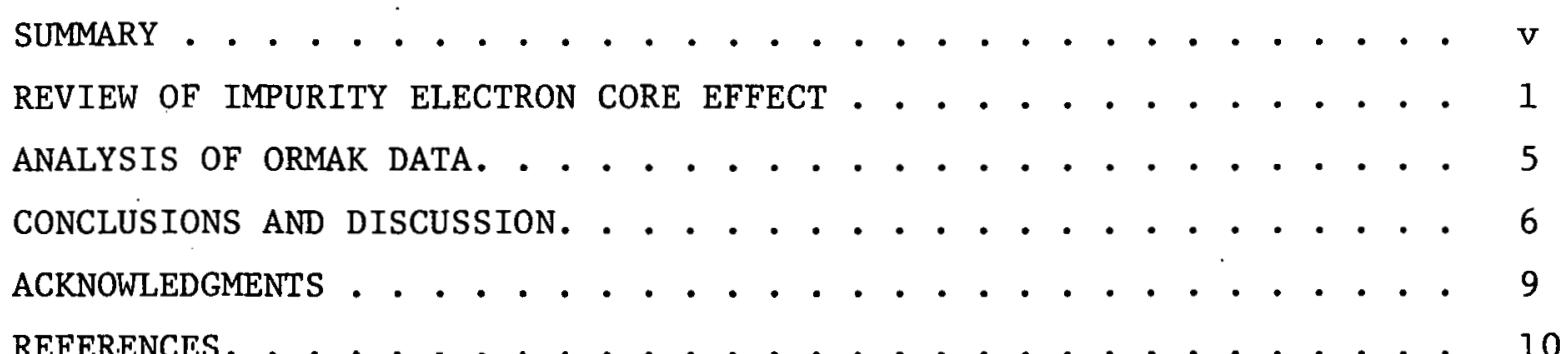

REFERENCES. . . . . . . . . . . . . . ....... 10 
THIS PAGE

WAS INTENTIONALLY

LEFT BLANK 
The impurity electron core effect on plasma resistance treated by Kirillov et al. 1 is included in the analysis of ORMAK discharge data to ascertain whether a significant reduction will occur in the value of $\langle Z\rangle$ determined from the resistance anomaly calculation. Results indicate that only elements of high atomic number (such as gold) will reduce $\langle\mathrm{Z}\rangle$ significantly (about 15\%). Iron $\langle Z\rangle$ is reduced about $5 \%$. This is contrary to the analysis by Kirillov et al. ${ }^{1}$ of TM-3 data which was taken early in the discharge when the impurity stripping was still in progress. Because the core effect varies roughly as $z_{j}^{-2}\left(z_{j}\right.$ being the average charge state of the impurity), a more pronounced reduction in $\langle Z\rangle$ will occur early in the discharge when the impurity stripping is incomplete. 
Kirillov et a1.1 attempt to explain the observed tokamak resistance anomalies, which lie in the range of 2 to 50 for TM-3, by the presence of ionized heavy impurities, such as iron, molybdenum, tungsten, etc. However, the larger anomalies required impurity ion densities larger than what might reasonably occur experimentally. In an attempt to reduce the required impurity ion densities, the effect of the residual electronic core on the momentum transfer cross section for electron-impurity collisions is considered. The residual electrons are assumed to reside in a smeared electron cloud surrounding the nucleus rather than having the net charge located at a point in the nucleus. The Thomas-Fermi model is used to calculate the electron core effect.

Kirillov et al. define the anomaly factor, $A$, as the ratio of the actual plasma resistance to the theoretical resistance of a fully ionized hydrogen plasma. Thus,

$$
A=\sum_{j} \frac{F_{e j}^{f r}}{F_{e i}^{f r}}=\sum_{j} \frac{n_{j}<v v \sigma_{e j}>}{n_{j}<v v \sigma_{e i}>}
$$

where $F_{e j}^{f r}=-m_{e} n_{j}<v v \sigma_{e j}>$ is the frictional force between an electron and ions of species $j, v$ is the relative velocity between electrons and ions of species $j$, and $\sigma_{e j}$ is the momentum transfer cross section. The angle brackets above indicate averaging over a Maxwellian velocity distribution of electrons. The subscript $i$ refers to protons.

Using their notation, the momentum transfer cross section is written

$$
\sigma_{e j}=\int(1-\cos \theta) d \sigma=4 \pi \rho_{1}^{2} \int_{\text {min }}^{\max }[z-F(q)]^{2} \frac{d q}{q}
$$

where

$$
\begin{aligned}
& \rho_{1}=\frac{\mathrm{e}^{2}}{\mathrm{mv^{2 }}} \\
& q=\left|p-p^{\prime}\right| / \hbar=(2 \mathrm{mv} / \mathrm{h}) \sin (\theta / 2)
\end{aligned}
$$




$$
\begin{aligned}
& F(q)=\int_{0}^{r} 0 \quad n(r) \frac{\sin q r}{q r} 4 \pi r^{2} d r \\
& \mathrm{~N}_{e}=\int_{0}^{r_{0}^{o}} n(r) 4 \pi r^{2} d r=z-z_{j} .
\end{aligned}
$$

Here $\mathrm{m}$ is the electron mass, $\mathrm{n}(\mathrm{r})$ is the radially dependent density of electrons in the cloud surrounding the ion, $Z$ is the atomic numher of the impurity species, and $z_{j}$ is the average charge state. The total number of electrons in the impurity elestron sloud is $\mathrm{N}_{\mathrm{e}}$. The clectron cure form factor is $F(q)$ and is determined by Kirillov et al. from the ThomasFermi model. If $\mathrm{N}_{e}=0$ (i.e., fully stripped) there is no form factor and the usual coulomb cross section is obtained from Eq. (2).

After making some approximations, Kirillov et al, arrive at an expression for the momentum transfer cross section which is applicable to all electron energies. They perform the averaging procedure indicated by Eq. (1) and find that the core effect leads to a multiplicative correction factor, $t_{C}$, in the usual coulomb logarithm, i.e.,

$$
\begin{aligned}
& f_{C}=1+\lambda_{j} \\
& \lambda_{j}=\frac{\left(Z / Z_{j}\right)^{2}-1}{4 \Lambda_{j}} \ln \left[1+\frac{3}{2} \gamma^{4}\left(\frac{T_{e}}{R_{y}}\right)^{2}\right] \\
& \gamma=\frac{3}{2} \frac{N_{e}{ }^{2 / 3}}{Z} .
\end{aligned}
$$

and $\Lambda_{j}$ is the coulomb logarithm for species $j$.

$$
\left.\Lambda_{j}=\ln \frac{D}{Z_{j}} \rho_{\perp}\right)
$$

$D$ is the Debye length and $\rho_{1}$ is the ninety degree deflection impact parameter. $\mathrm{T}_{e}$ is the electron temperature (eV), and Ry is the Rydberg constant equal to $13.6 \mathrm{eV}$. The anomaly factor given by $\mathrm{Eq}$. (1). is then written as 


$$
A=1+\sum_{j} \frac{n_{j}}{n_{e}} z_{j}^{2}\left(1-\frac{1}{z_{j}}-\frac{\ln z_{j}}{\Lambda_{i}}+\frac{\Lambda_{j}}{\Lambda_{i}} \lambda_{j}\right)
$$

where the subscript $j$ refers to the $j$ th impurity species, and $\Lambda_{i}$ is the electron-ion (proton) coulomb logarithm.

The neutral term which appears in the corresponding equation derived by Kirillov et al. has been neglected here because of its smallness. The last term within the parentheses of $\mathrm{Eq}$. (11) represents the electron core effect. From Eq. (8), one can see that in the absence of a core, i.e., $z=z_{j}$, the core correction factor $f_{C}$ is unity and the $\lambda_{j}$ term in Eq. (11) is zero.

The anomaly factor $A$ may be arrived at in a different manner by defining $A$ to be the ratio of electron-impurity collision frequency $v_{e}^{Z=Z}$ to the electron-ion (proton) collision frequency $v_{e}^{Z=1}$. Thus,

$$
\nu_{e}^{Z=Z}=B\left(T_{e}\right) n_{i} \Lambda_{i}\left\{1+\sum_{j} \frac{n_{j} Z_{j}^{2}}{n_{i}} \frac{\Lambda_{j}}{\Lambda_{i}}\right\} .
$$

Here $\mathrm{B}\left(\mathrm{T}_{\mathrm{e}}\right)$ is the electron temperature dependent part which varies as $\mathrm{T}_{\mathrm{e}}^{3 / 2}$ and contains the appropriate constants. We now account for the impurity electron core effect by multiplying $\Lambda_{j}$ by $f_{C^{*}}$ Also,

$$
\Lambda_{j}=\Lambda_{i}-\ln z_{j}
$$

Then the anomaly factor becomes

$$
\begin{aligned}
A & =\frac{\nu_{e}^{Z=Z}}{\nu_{e}^{Z=1}}=\frac{n_{i}}{n_{e}}\left\{1+\sum_{j} \frac{n_{j} z_{j}^{2}}{n_{i}}\left[\left(1-\frac{1 n_{j}}{\Lambda_{i}}\right)\left(1+\lambda_{j}\right)\right]\right\} \\
& =\frac{n_{i}}{n_{e}}\left\{1+\sum_{j} \frac{n_{j} z_{j}^{2}}{n_{i}}\left[1-\frac{1 z_{j}}{\Lambda_{i}}+\frac{\Lambda_{j}}{\Lambda_{j}} \lambda_{j}\right]\right\} .
\end{aligned}
$$

From charge neutrality, we have 


$$
\frac{n_{i}}{n_{e}}=1-\sum_{j} \frac{n_{j} z_{j}}{n_{e}}
$$

Substituting into Eq. (15) we obtain

$$
A=1+\sum_{j} \frac{n_{j} z_{j}^{2}}{n_{e}}\left[1-\frac{1}{z_{j}}-\frac{1 z_{j}}{\Lambda_{i}}+\frac{\Lambda_{j}}{\Lambda_{i}} \lambda_{j}\right],
$$

which is the expression derived by kirillov et al.

The correction term $\lambda_{j}$ is 1 argest for elementc of high atomic uumber $\mathrm{Z}$ where

$$
\lambda_{j} \sim\left(\frac{z}{z_{j}}\right)^{2}
$$

Kirillov et al. gave an example of tungsten $(Z=74)$ ionized to $z_{j}=20$ at $\mathrm{T}_{e}=1 \mathrm{keV}$. They find $\lambda_{j}=0.8$. Thus a substantial part of the resistance anomaly may be explained by the electron core effect. In this example, the effective $-Z$ (or $\langle Z\rangle$ ) necessary to explain the resistance anomaly is approximately $80 \%$ lower than that withnut the sore consideration. 
ANALYSIS OF ORMAK DATA

The high $<\mathrm{Z}>$ obtained in ORMAK discharges has been a persistent problem in that the calculated $\langle Z\rangle$ necessary to explain the resistance anomaly has historically been larger than that inferred from experimentation. ${ }^{2}$ The question we now ask is, "Can the impurity electron core effect explain any significant part of the ORMAK resistance anomaly?"

The core effect has been incorporated into the static discharge data analysis program ZøRDIC. ${ }^{3}$ The results from the analysis of two different data sets are shown in Tables 1 through 4 . The $Z_{c}$ mode ${ }^{3}$ (i.e., $\langle Z\rangle$ considered to be constant across the plasma) is used here. We compare the results for a gold and an iron impurity model with and without the core effect. We immediately see that the iron model decreases $\langle Z>$ by only 4 to $5 \%$ (Tables 2 and 4). On the other hand, gold $(Z=79)$ decreases $\langle Z>$ by 14 to $16 \%$ (Tables 2 and 4$)$. Thus only impurities of high atomic number will contribute significantly to the reduction of $\langle Z\rangle$. In the case of the dataset $09025 \mathrm{~N}$. A, the core effect reduces $\langle Z\rangle$ from 8.0 to 6.9 for gold and from 8.0 to 7.7 for iron. The $x$-ray analyses ${ }^{4}$ of the same ORMAK data indicate $a<Z>$ of about 6 for an iron mode1, although there is a large experimental uncertainty. Such analyses have not been performed for a gold model. 
The electron core effect due to impurities of intermediate atomic number $Z$ (such as iron) will not appreciably reduce the $\langle Z\rangle$ necessary to explain the ORMAK resistance anomalies. The heavier impurities (such as gold) more appreciably reduce $\langle Z\rangle$, aithough not as significantly as for TM-3 reported by Kirillov et al. This discrepancy is due to the fact that the analyses performed on TM- 3 data are only $4 \mathrm{msec}$ into the discharge. The stripping process is still operative at this time, and the average charge state $Z_{j}$ is lower than the average charge state which is estimated with a temperature rise time of $\sim 15 \mathrm{msec}$ and thus is closer to the equilibrium state of ionization. Because $\lambda_{j} \sim z_{j}^{2}$ and because tungsten strips to about $\mathrm{Z}_{j} \sim 40$ for $\mathrm{T}_{e}=1 \mathrm{keV}$, the electron core effect will be about four times smaller than the non-steady-state example given by Kirillov et al.

We should also point out that the treatment of Kirillov et a1. neglects the core effects on terms associated with electron-electron collisions and the non-Maxwellian distribution of electrons. Perhaps the Spitzer-Härm ${ }^{5}$ problem should be reworked to include the impurity electron core effect. In addition, the treatment of Kirillov et al. does not include neoclassical effects. 
Table 1. The effect on the amount of iron and gold required to satisfy the resistance anomaly of dataset 09025N.A

\begin{tabular}{lcccc}
\hline & $\begin{array}{c}\mathrm{M}_{\mathrm{Fe}} \\
\text { (moles) }\end{array}$ & $\begin{array}{c}\mathrm{M}_{\mathrm{Au}} \\
\text { (moles) }\end{array}$ & $\begin{array}{c}\frac{\mathrm{n}_{\mathrm{Fe}}(0)}{\mathrm{n}_{\mathrm{e}}(0)} \\
(\%)\end{array}$ & $\begin{array}{c}\frac{\mathrm{n}_{\mathrm{Au}}(0)}{\mathrm{n}_{\mathrm{e}}(0)} \\
(\%)\end{array}$ \\
\hline No core & $7.0 \times 10^{-7}$ & $2.2 \times 10^{-7}$ & 1.0 & 0.30 \\
Core & $6.7 \times 10^{-7}$ & $1.9 \times 10^{-7}$ & 0.95 & 0.26 \\
$\% \Delta$ & 4.3 & 14.0 & 5.0 & 13.0 \\
\hline
\end{tabular}

Table 2. The effect on the $\langle Z\rangle$ of dataset 09025N.A

\begin{tabular}{ccc} 
& $<\mathrm{Z}\rangle_{\mathrm{Fe}}$ & \multicolumn{2}{c}{${ }_{\mathrm{Au}}$} \\
\hline No core & 8.0 & 8.0 \\
Core & 7.7 & 6.9 \\
$\% . \Delta$ & 3.8 & 14.0 \\
\hline
\end{tabular}


Table 3. The effect on the amount of iron and gold required to satisfy the resistance anomaly of dataset $08185 \mathrm{~N} . \mathrm{B}$

\begin{tabular}{lcccc}
\hline & $\begin{array}{c}\mathrm{M}_{\mathrm{Fe}} \\
\text { (moles) }\end{array}$ & $\begin{array}{c}\mathrm{M}_{\mathrm{Au}} \\
\text { (moles) }\end{array}$ & $\begin{array}{c}\frac{\mathrm{n}_{\mathrm{Fe}}(0)}{\mathrm{n}_{\mathrm{e}}(0)} \\
(\%)\end{array}$ & $\begin{array}{c}\frac{\mathrm{n}_{\mathrm{Au}}(0)}{\mathrm{n}_{\mathrm{e}}(0)} \\
(\%)\end{array}$ \\
\hline No core & $4.3 \times 10^{-7}$ & $1.4 \times 10^{-7}$ & 1.35 & 0.44 \\
Core & $4.0 \times 10^{-7}$ & $1.2 \times 10^{-7}$ & 1.32 & 0.39 \\
$\% \Delta$ & 7.5 & 14.0 & 2.2 & 11.0 \\
\hline
\end{tabular}

Table 4. The effect on the $\langle Z>$ of the dataset 08185 N.B

\begin{tabular}{lcc} 
& $<>_{\mathrm{Fe}}$ & ${ }^{<\mathrm{Z}\rangle_{\mathrm{Au}}}$ \\
\hline No core & 9.6 & 9.6 \\
Core & 9.1 & 8.1 \\
$\% \Delta$ & 5.2 & 16.0 \\
\hline
\end{tabular}




\section{ACKNOWLEDGMENTS}

The author would like to thank A. Mense and M. Murakami for their very helpful discussions during this investigation. Thanks. are also extended to M. Murakami for providing the data for analysis. 


\section{REFERENCES}

1. V. D. Kirillov, B. A. Trubnikov, and S. A. Trushin, "Role of Impurities in Anomalous Plasma Resistance," Sov. J. PZasma Phys. . 1: 2 (March-April 1975).

2. L. A. Berry et al., Proc. 5th Intz. Conf. on Plasma Physics and Controlzed Nuclear Fusion Research, 1: 101 (1975).

3. D. L. Shaeffer and M. Murakami, "ZøRDIC, a New ORMAK Data Analysis Code with Impurity Modeling," ORMAK Technical Memo 230 (September 1976).

4. G. Jahns and M. Murakami (ORNL), private communication.

5. L. Spitzer and R. Härm, Phys. Rev. 89: 977 (1953). 
ORNL/TM-5745

INTERNAL DISTRIBUTION

1. C. F. Barnett
2. L. A. Berry
3. C. E. Bush
4. J. D. Callen
5. J. F. Clarke
6. R. E. Clausing
7. R. J. Colchin
8. E. C. Crume
9. J. L. Dunlap
10. P. H. Edmonds
11. A. C. England
12. C. A. Foster
13. J. T. Hogan
14. H. C. Howe
15. R. C. Isler
16. P. W. King
17. G. L. Jahns
18. T. C. Jernigan
19. G. G. Kelley
20. H. E. Ketterer
21. J. F. Lyon

22. D. G. McAlees

23. A. T. Mense

24. J. T. Mihalczo

25. M. Murakami

26. R. V. Neidigh

27. G. H. Neilson

28. V. K. Pare

29-36. D. L. Shaeffer

37. D. Steiner

38. L. D. Stewart

39. D. W. Swain

40. J. B. Wilgen

41. W. R. Wing

42. S. J. Zweben

43-44. Central Research Library

45. Document Reference Section

46-47. Laboratory Records Department

48. Laboratory Records, ORNL-RC

49. ORNL Patent Office

50-51. Fusion Energy Division Library

52. Fusion Energy Reports Office

\section{EXTERNAL DISTRIBUTION}

53. C. M. Braams, FOM-Instituut voor Plasma-Fysica, Rijnhuizen, Jutphaas, the Netherlands

54. A. M. Budker, Nuclear Physics Institute, Siberian Academy of Sciences, Novósibirsk 90 , U.S.S.R.

55. Prof. Piero Caldirola, Laboratorio di Fisica del Plasma ed Elettronica Quantistica del C.N.R., Via Celoria 16, 20133 Milano, Italy

56. Department of Nuclear Engineering Sciences, 202 Nuclear Science Center, University of Florida, Gainesville, FL 32611

57. Library, Centre de Recherches en Physique des Plasmas, 21 Avenue des Bains, 1007 Lausanne, Switzerland

58. T. Consoli, Centre d'Etudes Nucleaires de Grenoble, Avenue des Martyrs-38-Grenoble, France

59. Anne Davies, Tokamak Systems Branch, Division of Magnetic Fusion Energy, Mail Station G-234, Energy Research and Development Administration, Washington, DC 20545 
60. S. 0. Dean, Office of Confinement Systems, Division of Magnetic Fusion Energy, Mail Station G-234, Energy Research and Development Administration, Washington, DC 20545

61. Director, Technical Library, Defense Atomic Support Agency, Sandia Base, Albuquerque, NM 87115

62. A. M. Dupas, Documentation S.I.G.N., Department de la Physique du Plasma et de la Fusion Controlée, Association EURATOM-CEA sur la Fusion, Centre d'Etudes Nucleaires, BP 85 Centre du Tri, 38041 Grenoble CEDEX, France

63. O. C. Eldridge, Physics Department, Hunter College/CUNY, 695 Park Avenue, New York, NY 10021

64. H. P, Eubank, Plasma Physics Laboratory, Princeton University, Princeton, NJ 08540

65. H. K. Forsen, Exxon Nuclear Co., Inc., 777 106th Avenue, NE, Bellevue, 'WA 98004

66. T. K. Fowler, University of Callfornia, Lawrence Rudiation Laboratory, P.0. Box 808, Livermore, CA 94551

67. H. P. Furth, Plasma Physics Laboratory, Princeton University, Princeton, NJ 08540

68. R. W. Gould, Protessor of Electrlcal Ellyineering and Phyoice, Bldg. 116-81, Cal1fornia Institute of Technology, Pasadena, CA 91109

69. Harold Grad, Courant Institute, New York University, 251 Mercer Street, New York, NY 1.0012

7U. H. K. Grlem, Depärtïent of Phyoico, University nf Maryland, College Park, MD 20742

71. G. Guest, General Atomic Co., P.O. Box 81608, San Diego, CA 92138

72. I. Gverdsiteli, Physico-Technical Institute, Georgian Academy of Sciences, Sukhumi, U.S.S.R.

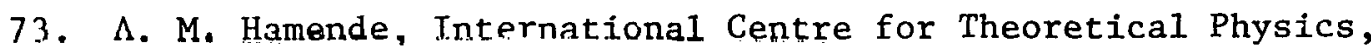
Trieste, Italy

74. Research Laboratory of Electronics, Document Room 36-412, Attention $\mathrm{J}$. Hewitt, Massachusetts Institute of Technology, Cambridge, MA 02139.

75. T. Hiraoka, Japan Atomic Energy Research Institute, Tokai, Ibaraki, Japan 
76. P. Hubert, Service de Recherches sur la Fusion Controlée, Centre d'Etudes Nucleaires, Fontenay-aux-Roses (Seine), France

77. K. Husimi, Institute for Plasma Physics, Nagoya University, Nagoya, Japan

78. D. W. Ignat, Division of Magnetic Fusion Energy, Mail Station G-234, Energy Research and Development Administration, Washington, DC 20545

79. E. E. Kintner, Division of Magnetic Fusion Energy, Mail Station G-234, Energy Research and Development Administration, Washington, DC 20545

80. E. Komar, D. V. Efremov Scientific Research Institute of ElectroPhysical Apparatus, Leningrad, U.S.S.R.

81. H. E. Knoepfel, Laboratorio Gas Ionizzati, C.P. 65, 00044 Frascati (Roma) Italy

82. Librarian, Physical Sciences Laboratory, P.0. Box 6, Stoughton, WI 53589

83. Librarian, Department of Physics and Astronomy, University of Iowa, Iowa City, IA 52240

84. Librarian, Institute for Plasma Physics, 8046 Garching bei Munchen, Federal Republic of Germany

85. Librarian, Culham Laboratory, Abingdon, Oxfordshire, OX14 3DB, England

86. Plasma Physics Library, Plasma Phyșics Laboratory, Princeton University, P.0. Box 451, Princeton, NJ 08540

87. M. J. Lubin, Department of Mechanical and Aerospace Sciences, Universtty of Rochester, Rochester, NY 1.4627

88. G. H. Miley, Professor, Department of Nuclear and Electrical Engineering, 214 Nuclear Engineering Laboratory, University of Illinois, Urbana, IL 61801

89. T. Ohkawa, General Atomic Company, P.0. Box 81608, San Diego, CA 92138.

90. D. Palumbo, Directorate General for Research and Training, EURATOM, 51 Rue Belliard, Brussels 5, Belgium

91. Plasma Laboratory Reading Room, Room 20A-222; Massachusetts Institute of Technology, Cambridge, MA 02139

92. F. Prevot, Chef du Service de Confinement des Plasmas, C.E.A., B.P. No, 6, 92 Fontenay-aux-Roses (Seine) France 
93. M. S. Rabinovich, Lebedev Institute of Physics, Academy of Sciences of the U.S.S.R., Leninsky Prospect 53, Moscow, U.S.S.R.

94. Center for Plasma Physics and Thermonuclear Research, Physics Building 330, University of Texas, Austin, TX 78712

95. Research Information Center, Institute of Plasma Physics, Nagoya University, Nagoya, Japan

96. F. L. Ribe, Los Alamos Scientific Laboratory, P.0. Box 1663, Los Alamos, NM 87544

97. D. J. Rose, Massachusetts Institute of Technology, Room 24-210, Cambridge, MA Ü139

98. Eugene Velikov, Thermonuclear Lahnrat,nry, Kurchatov Inotitute of Atomic Energy, 46 U1itsa Kurchatova, Post Box 3402, Moscow, U.S.S.R.

99. H. H. Woodson, Department of Electrical Engineering, University of Texas, Austin, TX 78712

100. Director, Research and Technical Support Division, ERDA-ORO, P.O. Box E, O:ak Ridge, TN 37830

101-127. 'lechnical Information Center, P.0. Box 62, Oak Ridge, TN 37830 